\title{
Congreso Regional de Atención Primaria vs Medicina de Familia
}

\begin{abstract}
Sr. Editor:
Hace dos años, tras la edición de Toledo, creí necesario hacer una llamada de atención sobre lo que consideraba una "deriva" del congreso regional que se iba alejando progresivamente del modelo SCAMFYC ${ }^{1}$. Partía en mis argumentos del espíritu que animó la organización de las primeras jornadas, antes de la convergencia con SEMERGEN. El objetivo fundamental era facilitar la difusión de los trabajos de investigación desarrollados en nuestros centros de salud, al tiempo que servir de foro de debate para los profesionales. Planteé en aquella carta una serie de cuestiones fundamentales que en mi opinión había que corregir. Lejos de conseguirlo, el reciente congreso de Albacete ha mostrado un grave empeoramiento de la situación.
\end{abstract}

Señalaba entonces que la evolución del modelo de congreso había ido progresivamente alejándose de los estándares que en su día defendió SCAMFYC, con simposios de laboratorios abriéndose sitio, los talleres copando el tiempo del congreso, los casos clínicos invadiendo el espacio de las comunicaciones, y con los temas de las ponencias adquiriendo un carácter cada vez más alejado de lo que podríamos llamar el perfil bio-psico-social del médico de familia.

Pues bien, en el congreso de Albacete se ha "secuestrado" más de la mitad de la duración del mismo para entregarlo a talleres. No quiero abundar en la reiteración de los temas de los mismos año tras año, pero sí subrayar que de 7 , estaban financiados por la industria farmacéutica 4 , y en uno incluso el ponente era del propio laboratorio. Más reiteración monotemática en la primera mesa, también patrocinada por la industria farmacéutica. $\mathrm{Y}$, para una mesa que tenía algo importante que decir, se la relegó al último lugar, con una ridícula hora y media. Justo es reconocer, sin embargo, el esfuerzo de nuestros representantes en los comités organizador y científico por que pudiéramos contar con ponentes que pusieron un indiscutible toque de calidad. Sin querer ser exhaustivo, hay que subrayar la intervención de Félix Miguel frente a los arquetipos de "comités de expertos"/industria farmacéutica, o la pujanza de los Drs Pisco o Minué, que pusieron en evidencia (más si cabe) las carencias del gerente del SESCAM.

Por supuesto que para comunicaciones tampoco había tiempo. Hemos pasado de dar cabida a unas
20-25 comunicaciones orales en las jornadas previas a la convergencia con SEMERGEN, a reducirlas a la mitad, con planteamientos tan poco lógicos como presentar comunicaciones a una mesa antes de la misma. Con todo, en mi opinión lo más grave es que la mitad de los trabajos presentados en Albacete eran casos clínicos. Algunos de ellos no tendrían interés ni para una sesión en un centro de salud.

Otro tema polémico es el del comité científico. Ya señalaba en aquella carta que, desde mi punto de vista, se trata de una labor eminentemente técnica que requiere el concurso de expertos, entendiendo por tales aquellos con formación específica en metodología de la investigación y con experiencia personal en la misma, y me manifestaba abiertamente en contra de las cuotas, a las que nuestro comité científico está atado doblemente: por provincia y por sociedad científica. Pues bien, en este aspecto hemos pasado no solo de admitir a cualquiera en dicho comité, sino además a hacerle responsable de la presidencia del mismo.

Aunque para algunos lo pueda parecer, creo que el tema que planteo no es banal. Está en juego la esencia misma de nuestra especialidad, tal y como se ha concebido desde la SEMFYC. Hablo de valores como esfuerzo, superación, mérito... ¿Quién va a querer invertir innumerables horas en realizar un trabajo de investigación cuando en una tarde deja hecho un caso clínico que al final del congreso le reporta una certificación similar?

Nos lamentamos de que muchos residentes sigan la ley del mínimo esfuerzo, se dejen "seducir" por las "trampas" que tiende la industria farmacéutica, o tengan preferencia por otras sociedades científicas. La solución no está en darles nosotros más de lo mismo, sino, al contrario, en marcar una clara línea de separación.

\section{BIBLIOGRAFÍA}

1. Escobar Rabadán, F. La deriva del congreso regional o el congreso regional a la deriva. Rev Clin Med Fam. 2010; 3: 146-7.

Francisco Escobar Rabadán

Médico de Familia. Centro de Salud Universitario Zona IV de Albacete 